\author{
Original
}

\title{
Physical, thermal, and mechanical properties of polypropylene composites filled with rattan nanoparticles
}

\author{
Siti Nikmatin ${ }^{\mathrm{a}}$, Achmad Syafiuddin ${ }^{\mathrm{b}, \mathrm{c}, *}$, Ahmad Beng Hong Kueh ${ }^{\mathrm{d}}$, Akhiruddin Maddu ${ }^{\mathrm{a}}$ \\ ${ }^{a}$ Department of Physics, Faculty of Mathematics and Natural Sciences, Bogor Agricultural University, 16680 Bogor, Indonesia \\ ${ }^{\mathrm{b}}$ Department of Geophysics Engineering, Faculty of Civil Engineering and Planning, Institut Teknologi Sepuluh Nopember, 60111 Surabaya, Indonesia \\ ${ }^{\mathrm{c}}$ Department of Environmental Engineering, Faculty of Civil Engineering, Universiti Teknologi Malaysia, 81310 UTM Johor Bahru, Johor, Malaysia \\ ${ }^{\mathrm{d}}$ Construction Research Centre (CRC), Faculty of Civil Engineering, Universiti Teknologi Malaysia, 81310 UTM Johor Bahru, Johor, Malaysia
}

Received 16 September 2016; accepted 20 March 2017

Available online 25 August 2017

\begin{abstract}
Natural fillers are recognized as the materials that feature a poor fiber/matrix interaction. As a result, their composites behaviors are directly compromised. Existing evidence has exhibited that nanoparticle fillers can be employed as an alternative size to overcome this problem. We thus examined in this study the effects of rattan filler of nanoparticle size on the physical, thermal, and mechanical properties of the composite. Neat polypropylene (PP), PP with 5\% rattan nanoparticle (PP/R5), and PP with 5\% glass fiber (PP/FG5) were considered. For performance assessment, particle size analysis, morphology, X-ray diffraction, thermal inspection, and mechanical tests were carried out. The highest degree of crystallinity was discovered in PP/R5. Tensile properties of both PP/FG5 and PP/R5 were comparable although the former demonstrated higher moduli of elasticity and rupture. Well-distributed constituents were displayed in PP/R5 by means of morphological study, which offered insight into its highest average hardness, maximum strain, and therefore its advantageous ductile behavior compared to the other considered materials.

(C) 2017 Universidad Nacional Autónoma de México, Centro de Ciencias Aplicadas y Desarrollo Tecnológico. This is an open access article under the CC BY-NC-ND license (http://creativecommons.org/licenses/by-nc-nd/4.0/).
\end{abstract}

Keywords: Rattan nanoparticle; Natural filler; Mechanical properties; Polypropylene; Twin extrusion molding

\section{Introduction}

The abundant availability of natural fibrous materials presents a widespread potential that can be smartly exploited in various sectors of industry (Alves et al., 2010; Ashori, 2008; Bahari \& Krause, 2016; Joshi, Drzal, Mohanty, \& Arora, 2004; Lopes, Ferreira, Russo, \& Dias, 2015; Versino, López, \& García, 2015). The utilization of these natural resources in numerous engineering applications may straightly support the global developments particularly in the aspects of socio-economy, ecosystem, and green technologies. At present, the applications of natural resources as bio-filler or reinforcement in composite materials are among the most attractive research subject. This is because the specific mechanical behaviors of some nat-

\footnotetext{
* Corresponding author.

E-mail address: udenfisika@gmail.com (A. Syafiuddin).

Peer Review under the responsibility of Universidad Nacional Autónoma de México.
}

ural fibers are closely comparable to those of synthetic glass fibers (Vilaseca et al., 2010). Furthermore, pressing motivation is derived from the heightened concern on the long-term adverse impact of synthetic fibers on the environment. To date, several studies have been carried out to investigate advantages and disadvantages of natural fibers when incorporated into matrix as composites (Arrakhiz et al., 2012; Ataeefard \& Moradian, 2011; Balakrishna, Ismail, \& Othman, 2014; Baniasadi, Ramazani, \& Javan, 2010; Essabir et al., 2013; Jamil, Ahmad, \& Abdullah, 2006; Ochi, 2008; Ruksakulpiwat, Sridee, Suppakarn, \& Sutapun, 2009). Ruksakulpiwat et al. (2009) observed that the tensile strength and Young's modulus of composites with up to $10 \%$ of natural rubbers are higher than those of polypropylene (PP). Ochi (2008) reported that the tensile strength, flexural strength, and modulus of elasticity of kenaf fiber-reinforced composites increase linearly up to a fiber content of 50\%. Also, Jamil et al. (2006) found that the tensile modulus and hardness of polyethylene/natural rubber blends increase via the introduction of rice husk loadings. Essabir 
et al. (2013) observed that the decomposition temperature of PP composites reinforced with Nut-shells of Argan (NA) particles decreases from $256^{\circ} \mathrm{C}$ to $230^{\circ} \mathrm{C}$ by increasing the particle loading from 10 to $25 \mathrm{wt}$ \%. Balakrishna et al. (2014) noticed that incorporating composite rattan powder and 10 phr kaolin fillers in polypropylene raise $12 \%$ the composite tensile modulus compared with 0, 2, 4, and 6 phr kaolin fillers. Ataeefard and Moradian (2011) reported that the surface roughness of polypropylene based nanocomposites can be increased by including nanoclay and by raising its amount. Arrakhiz et al. (2012) obtained the highest improvement of about $35 \%$ in Young's modulus of PP reinforced with esterified alfa fiber when compared to those without reinforcement. A disadvantage of the natural filler was, however, reported by Baniasadi et al. (2010) who found that the thermal conductivity and thermal diffusivity of the composites decrease with banana fiber loading.

Recently, nanoparticles are highly regarded as the filler materials to improve physical and mechanical properties of the composites. Several works have been conducted to explore their benefits on physical and mechanical properties of the composites (Goyal, Tiwari, Mulik, \& Negi, 2007; Lim, Zeng, \& He, 2010; Lin et al., 2015; Wang, Lu, Ding, Zhang, \& Chan, 2016; Zhang \& Singh, 2004). Zhang and Singh (2004) found that, for the case of $4.5 \%$ volume fraction of well-bonded $\mathrm{Al}_{2} \mathrm{O}_{3}$ particles added to the unsaturated polyester, the fracture toughness can be increased by almost $100 \%$. To emphasize the usefulness of nanoparticle fillers, Wang et al. (2016) reported that the smaller sized nano- $\gamma-\mathrm{Al}_{2} \mathrm{O}_{3}$ particles perform better than the larger sized nano- $\alpha-\mathrm{Al}_{2} \mathrm{O}_{3}$ particles in reinforcing natural rubber. Recently, Lin et al. (2015) noticed that the composite matrix incorporating the $\mathrm{ZnO}$ nanoparticles doped graphene (nano-ZnO-GE) exhibits a higher wet grip property and lower rolling resistance compared with those of $\mathrm{NR} /$ conventional- $\mathrm{ZnO}$ composite. Lim et al. (2010) concluded that mechanical properties, namely, tensile modulus, tensile strength, and fracture toughness are affected by the geometry of the particles. Goyal et al. (2007) observed that poly(ether ether ketone) (PEET) containing nano-aluminum oxide $\left(\mathrm{n}-\mathrm{Al}_{2} \mathrm{O}_{3}\right)$ filler loading exhibits an improved thermal stability, crystallization, and coefficient of thermal expansion.

To date, fillers in the under-explored powder form are becoming more popular in the production of hybrid composites that utilizes natural resources (Balakrishna, Ismail, \& Othman, 2012; Muniandy, Ismail, \& Othman, 2012; Nikmatin, Syafiuddin, Kueh, \& Purwanto, 2015). Muniandy et al. (2012) reported that the tensile strength, elongation at break, stress at $100 \%$ elongation (M100), and stress at 300\% elongation (M300) of all composites increase corresponding to the rise in the carbon black (CB), mica, and calcium carbonate $\left(\mathrm{CaCO}_{3}\right)$ filler-loading ratios. Balakrishna et al. (2012) obtained from a series of measurements that the tensile strength, elongation at tensile failure, and impact strength decrease; while the stabilization torque, thermal stability, and water absorption increase, if the rattan filler loading is raised from 0 to $40 \mathrm{phr}$ in PP composites. It is worthwhile to see that the majority of the above-discussed studies only focus on the physical and mechanical properties of the composites with fillers in the micrometer size range. Recently, Nikmatin et al. (2015) reported that incorporating rattan in nanoparticle size into polypropylene increases the thermal stability of the composite. Their study is, however, limited to investigating the rattan nanoparticle effect as filler for composite on thermal properties only. Therefore, it is of great importance to also examine the effects of rattan nanoparticle on the physical and mechanical properties of composites for further exploration of material behaviors as well as associated potential applications.

Aligning to the aforementioned research gap, the present study aims to investigate the effects of rattan nanoparticles as filler in polypropylene on the physical, thermal, and mechanical properties of composites. Several investigations had reported that the incorporation of small amount of natural filler into polymer matrix especially in the nanometer range enhances the mechanical properties of composites (Ismail, Edyham, \& Wirjosentono, 2002; Kim, Moon, Kim, \& Ha, 2008; Tajvidi \& Ebrahimi, 2003). In the past, the effects of incorporating rattan nanoparticle into polypropylene with filler contents ranging from 2 to $20 \%$ on the composite behaviors had been examined (Nikmatin, 2012). The study found that the mechanical properties of the composites were the most optimal with $5 \%$ filler content. However, the mechanical performance decreased when the filler content was increased from $5 \%$ to $20 \%$. Therefore, the current study only focused on the implementation of $5 \%$ of rattan nanoparticles as the composite filler content. This paper is organized as follows. Immediately after the short outlining for the layout of the paper, a brief summary of the current work is first offered. Constituent materials used to fabricate the composite are then described. Next, the procedures for the preparation of fillers and composites are presented. This is then followed by the exploration methodologies and findings in terms of particle size analyses, X-ray diffraction patterns, morphological study, thermal inspection, and mechanical tests. This paper ends with conclusions and suggestions for future works.

In general, the present work has successfully prepared and investigated rattan nanoparticle-filled polypropylene as biocomposite material in terms of physical, thermal, and mechanical properties compared to neat PP and its composite with 5\% glass fiber. An optimal distribution of rattan nanoparticle size was obtained with $30 \mathrm{~min}$ of milling period. This study found that rattan nanoparticle-filled polypropylene has the highest degree of crystallinity, a better surface morphology, and the highest average hardness compared to all other studied materials. In conclusion, rattan with nanoparticle sizes in powder form has been proven to be potentially useful in improving the physical, thermal, and mechanical properties of composites.

\section{Materials and methods}

\subsection{Materials}

The raw material for the present study, rattan pole waste (see Fig. 1), was collected from Cirebon, West Java, Indonesia. Rattans are classified under the palm family (Palmae or Arecaceae). Currently, there are 610 different species under 13 genera in the world. They are chiefly available in the Southeast Asia region. For the matrix, we used the recycled polypropylene (PP) 


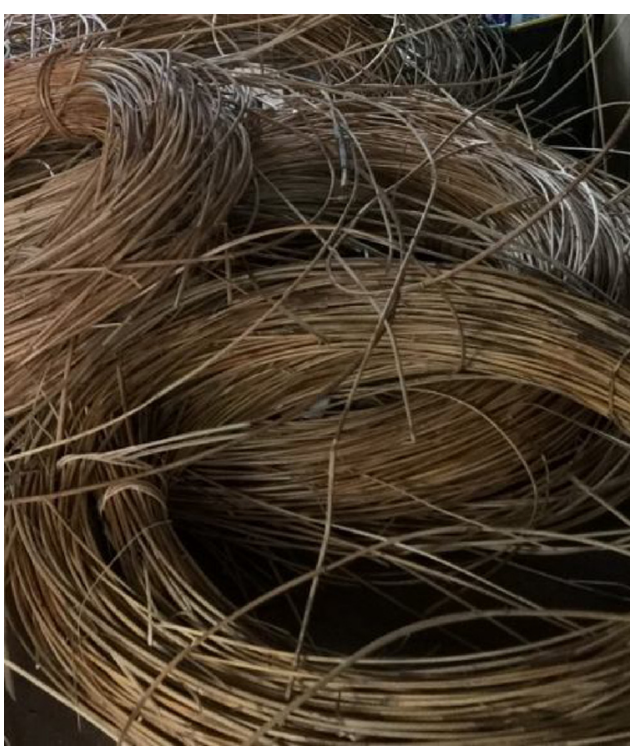

Fig. 1. Rattan poles waste.

supplied by PT MUB Jaya, Bogor, West Java. It has a melt flow index of $4.5 \mathrm{~g} \mathrm{~min}^{-1}$ at $230^{\circ} \mathrm{C}$ and a density of $0.95 \mathrm{~g} \mathrm{~cm}^{-3}$. For comparison purpose, we used synthetic glass fiber (E-Glass) having a density of $2.58 \mathrm{~g} \mathrm{~cm}^{-3}$, refractive index of 1.558 , softening point of $771^{\circ} \mathrm{C}$, and annealing point of $657^{\circ} \mathrm{C}$.

\subsection{Preparation of filler}

The rattan pole waste was first cleaned and then cut into small sizes using a knife. It was then dried in the oven at $100^{\circ} \mathrm{C}$ for 15 min to eliminate impurity and excessive moisture. Furthermore, milling and shaking were performed on the rattan pole waste, followed by sieving to an average particle size of $75 \mu \mathrm{m}$ (sieve $200 \mathrm{mesh}$ ). In the current study, a hammer mill with the rate of $25,000 \mathrm{rpm}$ was used to produce particles of the nanometer range. Hammer milling is a mechanical operation used to reduce the particle size with the combined actions of collision, shaking, and milling. In this process, three time variations of 15,30 , and 45 min were explored and applied to obtain particle sizes $<100 \mathrm{~nm}$.

\subsection{Preparation of nanocomposites}

The designations for studied materials associated with their filler compositions are listed in Table 1. For the composite, polypropylene as the matrix was reinforced by rattan nanoparticles, which act as the filler, in the company of the coupling agent maleic anhydride (MA). Due to hydrophilic and

Table 1

PP and composition of fillers in composites.

\begin{tabular}{ll}
\hline Designation & Filler type (percentage, \%) \\
\hline PP & - \\
PP/FG5 & Glass fiber (5) \\
PP/R5 & Rattan (5) (nanoparticle size) \\
\hline
\end{tabular}

hydrophobic properties of the nanofiller (rattan) and matrix (polypropylene), respectively, MA was employed to improve their interfacial interaction. This coupling agent had been proven useful in enhancing the physical-mechanical properties of composites (Dogu \& Kaynak, 2016; Essabir, Bensalah, Rodrigue, Bouhfid, \& Qaiss, 2016; Sombatsompop, Yotinwattanakumtorn, \& Thongpin, 2005; Thwe \& Liao, 2003). Note that a good bonding can be formed by the reduction in the particle size as well, in the current case by the use of the nanometer size range, due to a greater surface area. The smallest size range of rattan nanoparticles obtained from the hammer mill process was selected as filler for the composite. The composition of the composite was $5 \%$ filler, 3\% MA, and $92 \%$ matrix. As mentioned in the introduction, we focused on the incorporation of a small content of natural filler into polypropylene, in the current case $5 \%$, due to its better mechanical properties as reported by the previous works (Ismail et al., 2002; Kim et al., 2008; Nikmatin et al., 2015; Tajvidi \& Ebrahimi, 2003). For comparison purpose, synthetic composites with the composition of $5 \%$ glass fiber were also fabricated (PP/FG5). All samples were fabricated with the twin extrusion molding machine at a temperature of $190^{\circ} \mathrm{C}$, with a mixing speed of $45 \mathrm{rpm}$ for $3 \mathrm{~h}$ of mixing time, before cooled to a temperature of $40^{\circ} \mathrm{C}$.

\subsection{Particle size analyzer}

Examination of the particle size of rattan powder was done using the particle size analyzer (PSA), VASCO. VASCO is a dynamic light scattering measurement-based and fully agile nanoparticle size analyzer. For the examination, the rattan powder was put into the sample holder. It was performed for three sample types produced by 15,30 , and 45 min milling processes.

\subsection{X-ray diffraction analysis}

The X-ray diffraction diagrams were recorded by using the EMMA X-ray diffractometer, with operation capacities of $35 \mathrm{kV}$ and $28 \mathrm{~mA}$. The X-ray diffractometer was filtered with a radiation of $1.5 \AA$ in the $2 \theta$ range of $10^{\circ}-60^{\circ}$ with the steps of $0.02^{\circ}$ at a scanning rate of $2^{\circ} \mathrm{min}^{-1}$.

\subsection{Morphological study}

Examinations of the morphology and the composition of rattan fibers were carried out by means of Scanning Electron Microscopy (SEM) using JEOL JED model 2300 at a voltage of $20 \mathrm{kV}$. SEM micrographs were taken at 500 magnification. Sputter coated with gold was used on the fracture surfaces to prevent electrostatic charging and low image resolution during examinations.

\subsection{Thermal property inspection}

Thermal properties were analyzed by using the differential scanning calorimeter (model JADE, Perkin Elmer, USA). All the sample weights used in this study were in the range of $\pm 7.9 \mathrm{mg}$. The samples were assessed with a thermal scan 


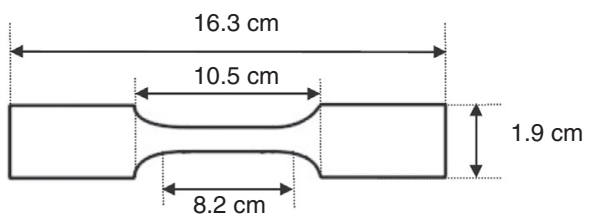

b

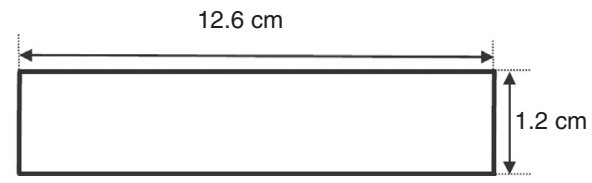

Fig. 2. Sample dimensions of composite for (a) tensile test and (b) bending and hardness tests.

with temperatures from $26^{\circ} \mathrm{C}$ to $444{ }^{\circ} \mathrm{C}$ at a heating rate of $10^{\circ} \mathrm{C} \mathrm{min}^{-1}$, under a nitrogen supply rate of $20 \mathrm{cc} \mathrm{min}^{-1}$. In the process, heat flow versus temperature change was monitored.

\subsection{Tensile test}

Tensile tests were carried out at the room temperature of $23^{\circ} \mathrm{C}$ with a relative humidity of $61 \%$. Dog bone-shaped specimens (see Fig. 2(a)) with overall dimensions of $16.3 \times 1.9 \times 0.4 \mathrm{~cm}$ were prepared. In the present study, a Shimadzu testing machine (EHF-EB20-40L) with a $50 \mathrm{kN}$ load cell was employed. Tensile tests were performed by a crosshead pulling at a rate of $1 \mathrm{~mm} \mathrm{~min}{ }^{-1}$ until the failure of the specimens. Three samples were tested for each composite type. The tests were performed according to the American Society for Testing and Materials (ASTM) standard D638.

\subsection{Bending test}

Bending tests were also carried out at the room temperature of $23{ }^{\circ} \mathrm{C}$ and a relative humidity of $61 \%$. Three samples with dimensions of $12.6 \times 1.2 \times 0.4 \mathrm{~cm}$ as shown in Figure 2(b) were tested for each composite type according to the ASTM D790 standard. A Shimadzu testing machine (AG-20KNG) was used to measure the bending properties of the composites. All tests were carried out at a crosshead speed of $2.8 \mathrm{~mm} \mathrm{~min}^{-1}$ until the failure of the specimen was reached.

\subsection{Hardness test}

Hardness tests were carried out using the Shimadzu testing machine (G21 series). The tests were performed using the Rockwell $\mathrm{R}$ method. Three samples with dimensions of $12.6 \mathrm{~cm} \times 1.2 \mathrm{~cm} \times 0.4 \mathrm{~cm}$ as shown in Figure 2(b) were examined for each composite. The samples were indented by using a steel sphere with a load of $100 \mathrm{kgf}$. The average of recorded data was reported as the Rockwell $\mathrm{R}$ hardness. The test procedure was conducted according to the ASTM E18 standard.

\section{Results and discussion}

\subsection{Sizing}

Figure 3(a)-(c) show the distribution of rattan particle sizes obtained from particle size analyses. As shown in Figure 3(a), the distribution of rattan particle sizes is concentrated within the range of $51-489 \mathrm{~nm}$, resulting from the $15 \mathrm{~min}$ milling process. There is a significant decrease in the rattan particle size from the initial $75 \mu \mathrm{m}$ to the nanoparticle size range. Hence, the milling period of $15 \mathrm{~min}$ can be considered as a good time span to reduce the rattan particle size. As shown in Figure 3(b) for the milling period of $30 \mathrm{~min}$, there is a further substantial decrease in the rattan particle size when compared to that shown in Figure 3(a).

In general, the increase in the milling period provides more force for the breaking event. Consequently, more energy produced from the milling is transferred into the particles. As a result, more cavitation and breakage are induced by the energy for further reduction in the particle sizes. Since all materials have a maximum elasticity, or rather strength under certain deformation, the particles can rupture if the applied force exceeds this ultimate value. Following this logic, the particle sizes become smaller after a longer milling period.

Figure 3(d) shows the distribution of rattan particle size for the milling period of $45 \mathrm{~min}$. Interestingly, the distribution exhibits an increase in particle sizes compared to those of 15 and $30 \mathrm{~min}$. As shown in Figure 3(d), the distribution of rattan particle size spreads within the range of 257 to $6762 \mathrm{~nm}$. From this observation, it is resolved that there exists a certain maximum period for the milling process for an optimal reduction of rattan particle size. Nikmatin et al. (2015) argued that increasing the milling period causes a rise in temperature in the holder, due to the accumulation of heat in the machine. After a certain duration, the temperature begins to play the role in assisting the recrystallization event. As a result, there exists a surge in particle sizes. Several studies had concluded that in the milling process, the milling period is a key factor affecting the resulted particle size (Chaisan, Yimnirun, \& Ananta, 2009; Khamman, Chaisan, Yimnirun, \& Ananta, 2007; Muniandy et al., 2012). The variation in the rattan nanoparticle size distribution found in the present study is in agreement with the Chaisan et al. (2009) and Khamman et al. (2007) findings. This trend of size gain has been further confirmed by Nikmatin et al. (2015) who also found that smaller nanoparticle sizes were not obtained after a certain threshold of milling period was exceeded. The reverse pattern in particle size distribution such as that observed here is due to a phenomenon defined as agglomeration (Inkyo et al., 2006). Therefore, we note the attractiveness to explore the optimal milling time for desired nanoparticle sizes in the future work.

\section{2. $X$-ray diffraction $(X R D)$ analysis}

The existence of glass fiber and rattan nanoparticle fillers can change the internal crystal structures and therefore the crystallinity of a composite. Figure 4 shows XRD patterns of the neat $\mathrm{PP}$ versus PP with various fillers as the composites. We can see that the major crystalline peak of each profile occurs at around 
a
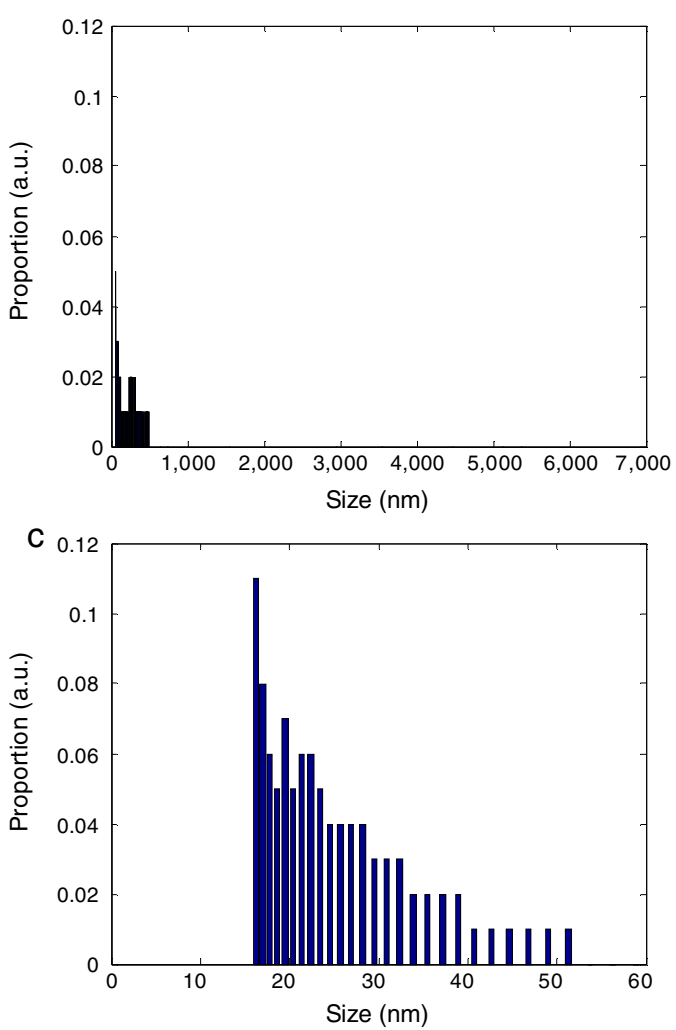

b
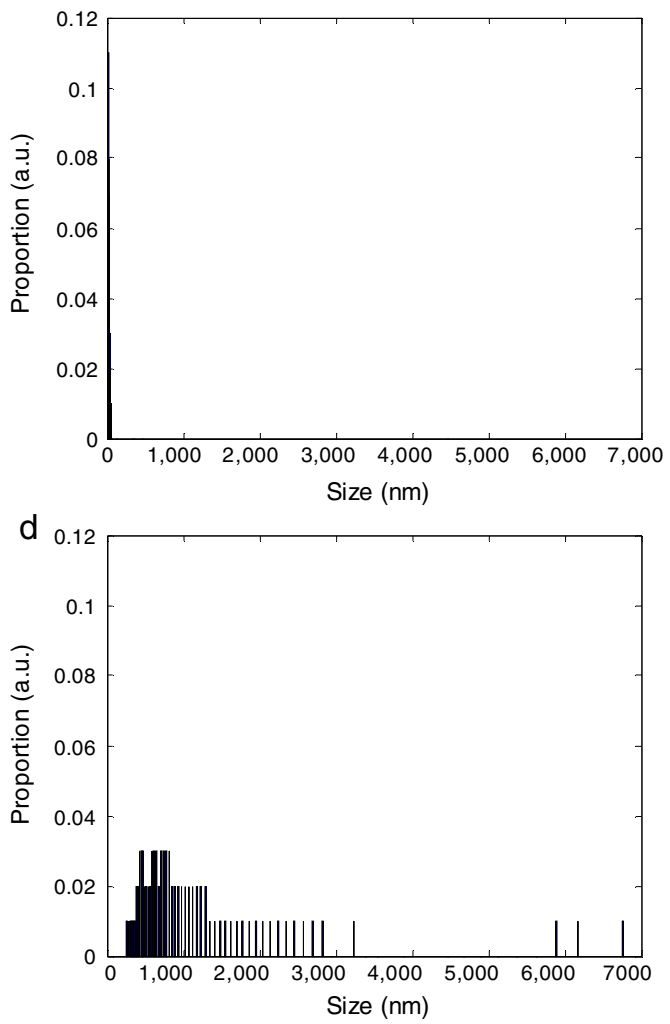

Fig. 3. Size distribution of rattan particles after (a) 15 min milling period, (b) 30 min milling period, (c) zoom in from (b), and (d) 45 min milling period.

$2 \theta=17.5^{\circ}$. It can be seen also that PP/R5 has the highest peak compared to others.

A lattice system presenting the microstructural makeup of a particular material can be described according to the relative lengths of the cell edges $(a, b$, and $c$ ) and the angles between them $(\alpha, \beta$, and $\gamma)$. We find that the neat PP is classified as orthorhombic symmetry with dimensions of $a=10.4, b=4.64$, $c=6.92$, and $\alpha=\beta=\gamma=90$. In addition, it has a degree of crystallinity of $35 \%$. PP/FG5 has a degree of crystallinity of $42 \%$. $\mathrm{PP} / \mathrm{R} 5$ is classified as monoclinic symmetry with dimensions of $a=7.87, b=10.31, c=10.13, \alpha=\gamma=90$, and $\beta=122$. It has a

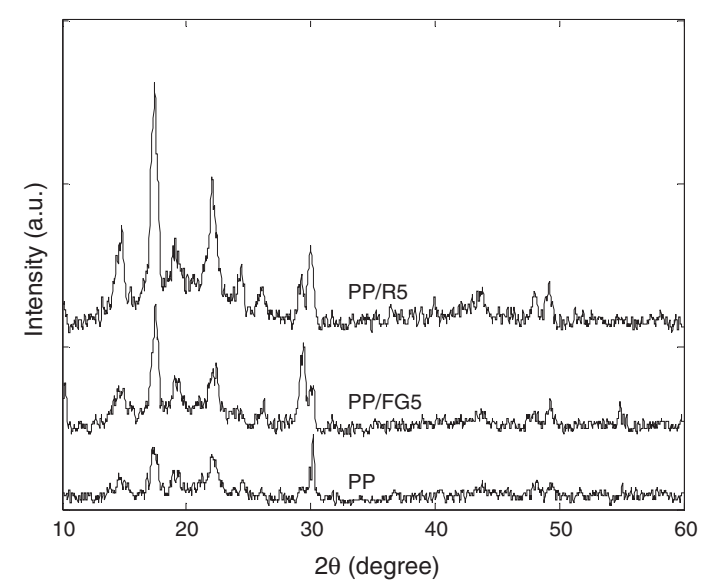

Fig. 4. X-ray diffractograms of neat PP and PP with various fillers. degree of crystallinity of $64 \%$. Thus, it is clear that PP/R5 has the highest degree of crystallinity compared to PP and PP/FG5. Talbott, Springer, and Berglund (1987) stated that the mechanical properties of semicrystalline thermoplastics depend strongly on the crystalline structure of the polymer. This is the first sign indicating that the rattan nanoparticles demonstrate a constructive attribute useful to be employed as fillers to improve their composite mechanical properties compared to the glass fiber.

\subsection{Morphological property}

Figure 5(a) and (b) show the surface morphology of PP/FG5 and PP/R5, respectively. In general, it is clear that there is a significant difference in the surface roughness of the composites. As expected, PP/R5 exhibits a better surface morphology. Voids indicated by black dots in the SEM are lesser compared to composite filled by glass fiber. The surface morphology of a composite is a key factor affecting the physical, thermal, and mechanical properties of the composites. A good contact or bonding between filler and matrix can be affected due to the morphological makeup of the mixture. Its effects on the thermo-mechanical behaviors of the composite are remained to be examined and are the subjects of the next sections. As previously mentioned, this study used rattan nanoparticles with sizes ranging from 16 to $51 \mathrm{~nm}$ for the composite filler (see Fig. 3(c)). However, the surface morphology depicted in Figure 5(b) reveals there are particle sizes of around $20 \mu \mathrm{m}$ in a small part of the cured composite. This can be attributed to the agglomeration 

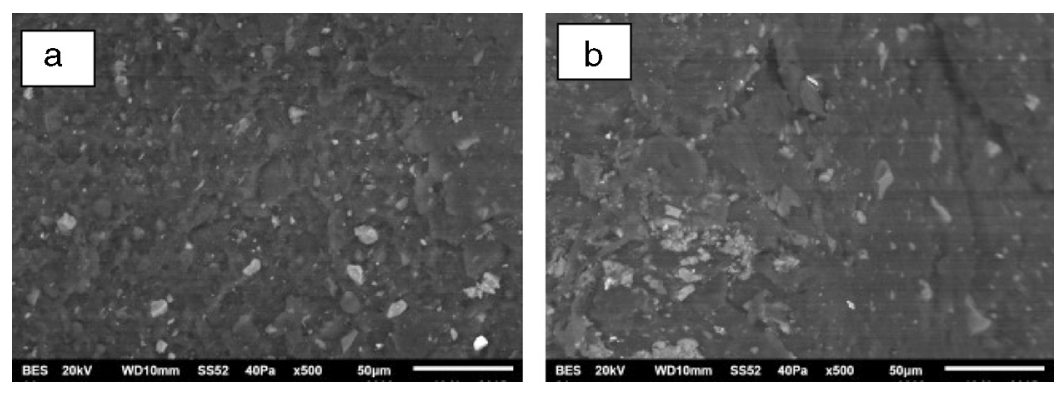

Fig. 5. Scanning electron microscopy of (a) PP/FG5 and (b) PP/R5.

of nanoparticles that typically occurs in the blending process. Mittal (2013) stated that nanoparticles commonly agglomerate during and after processing, causing non-uniform dispersion within the polymer matrix.

\subsection{Thermal property}

Figure 6(a)-(c) show the differential scanning calorimetry (DSC) curves of PP and PP with various fillers. From these figures, all DSC graphs show that the composites have two melting endothermic peaks. In Figure 6(c), at the first melting endothermic peak, PP/R5 has the onset temperature $\left(T_{\text {onset }}\right)$ at $121.44{ }^{\circ} \mathrm{C}$ and the end temperature $\left(T_{\text {end }}\right)$ at $131.39{ }^{\circ} \mathrm{C}$. In addition, at the second melting endothermic peak, PP has $T_{\text {onset }}$ at $150.10^{\circ} \mathrm{C}$ and $T_{\text {end }}$ at $168.24{ }^{\circ} \mathrm{C}$.

We notice that, at the first and the second peaks, PP/R5 has the highest $T_{\text {onset }}$ and $T_{\text {end }}$ compared to PP-based composite with glass fiber. The possible reason for this observation is the existence of cellulose in rattan that acts as an efficient nucleating agent for the crystallization of PP and this consequently increases the crystallization rate of PP (Amash \& Zugenmaier, 1998; Mi, Chen, \& Guo, 1997). These results are in agreement with those obtained by Qiu, Zhang, Endo, and Hirotsu (2003). Their study reported that $T_{\text {onset }}$ of polypropylene composite of high cellulose crystalline increases with the cellulose content from 0 to $60 \%$. Glass fibers are known as the noncrystallizable component since they inhibit the crystal growth of PP.

\subsection{Tensile test properties}

Figure 7 illustrates the tensile stress-strain relationship of PP and its composites with various fillers. All curves behave somewhat similarly with an early linear portion, defining the slope that reduces after a certain strain level, indicating the material

b
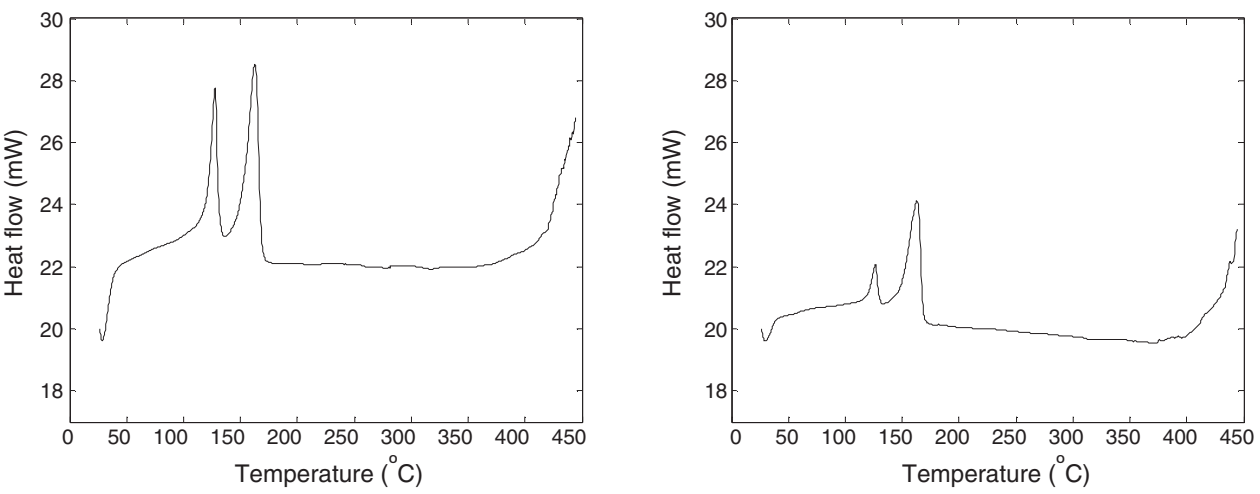

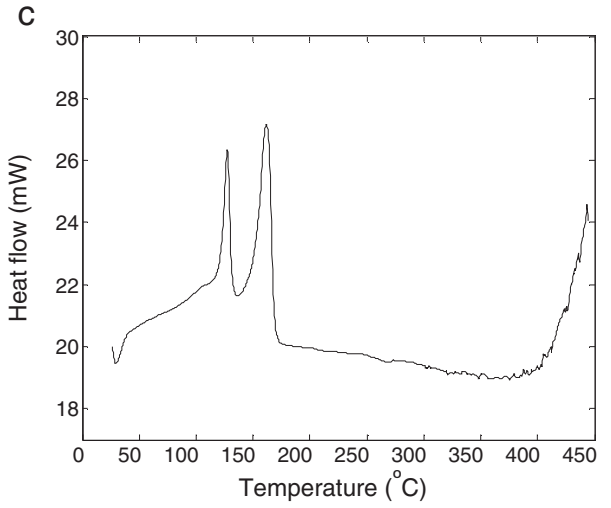

Fig. 6. Differential scanning calorimetry curves of (a) neat PP, (b) PP/FG5, and (c) PP/R5. 


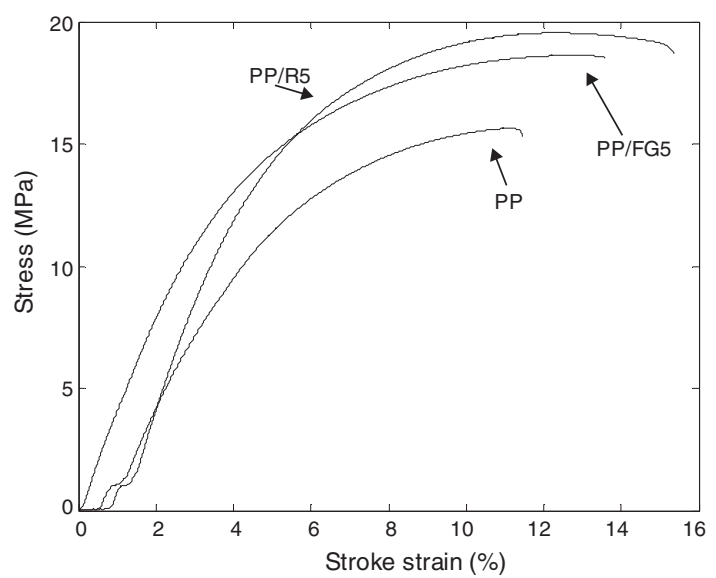

Fig. 7. Tensile stress-strain curves for PP and PP with various fillers.

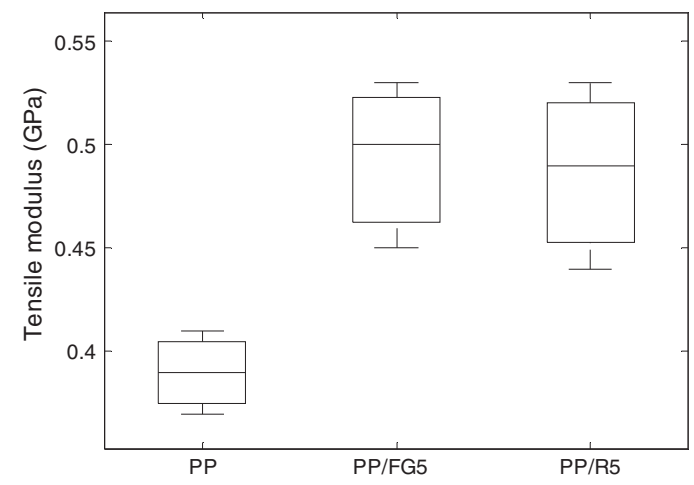

Fig. 8. Tensile modulus of neat PP and PP with various fillers.

stiffness that softens when the failure load is approached. Extracting all major tensile properties from these plots, they are then offered in terms of average, upper, and lower bounds for tensile modulus, strength, and maximum elongation in Figures $8-10$, respectively. It can be seen in Figure 8 that PP/FG5 has the highest average tensile modulus, which is followed by $\mathrm{PP} / \mathrm{R} 5$ and PP.

Although the tensile modulus of PP/R5 is found to be slightly lower than PP/FG5, it is still comparable to that of PP/FG5 and higher than PP. This suggests that, with the same composition of fillers, the tensile modulus of PP/R5 is similar to PP/FG5 and

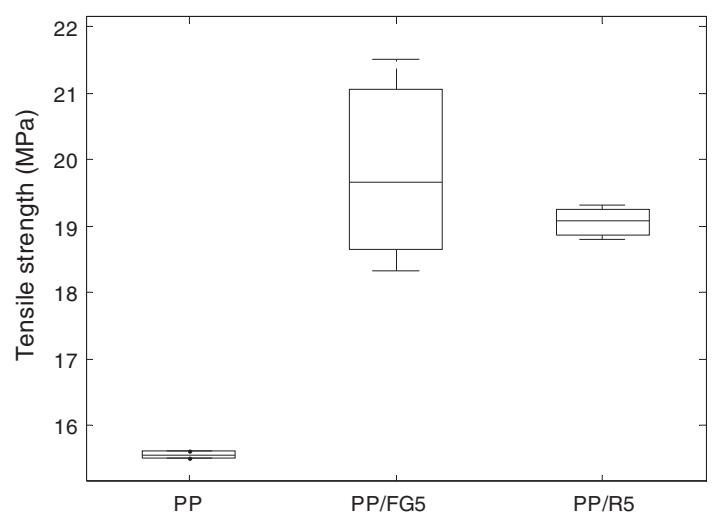

Fig. 9. Tensile strength of neat PP and PP with various fillers.

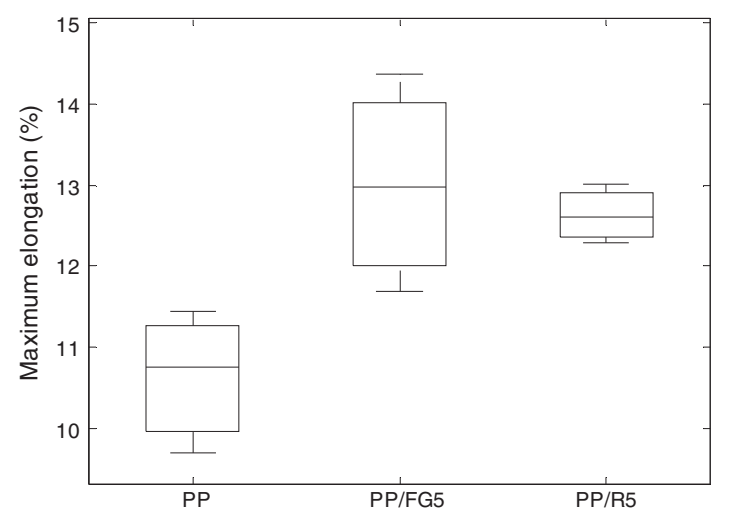

Fig. 10. Maximum elongation of neat PP and PP with various fillers.

greater than PP. These results imply that the rattan nanoparticle fillers can be used as an alternative filler to improve the tensile modulus and to replace the glass fibers in the composite.

Figure 9 summarizes the tensile strength of composites with various fillers including that of neat PP. It is noticed again that $\mathrm{PP} / \mathrm{FG} 5$ has the highest average tensile strength, and is followed by PP/R5 and PP sequentially. Although it is seen that, with the same filler content, glass fiber fillers produce a slightly higher strength than that of rattan nanoparticle, they are in general in the same order. Also, PP/R5 shows more consistent tensile strength compared with PP/FG5, its variation of which is somewhat larger. This observation offers motivation for our future work to improve the tensile strength with other fillers composition or chemical treatments, focusing chiefly on improving the bonding condition between fillers and matrix.

Figure 10 shows the maximum elongation of composites with various fillers and that of neat PP. The present study finds that PP/FG5 has the highest average elongation, and is followed by $\mathrm{PP} / \mathrm{R} 5$ and PP. It is interesting to see that $5 \%$ glass fiber filler exhibits a greater maximum elongation compared to neat PP. Also, PP/R5 demonstrates almost identical maximum elongation versus that of PP/FG5. Ismail et al. (2002) reported that the elongation decreases with the rise in the natural filler loading in the natural rubber composites. It is noteworthy to realize that in the present study, nanometer size range was employed for our studied fillers, while Ismail et al. (2002) used micrometer sizes. These results imply that composite fillers of nanometer size are able to improve the elongation properties, especially when a small amount of nanoparticle is used.

\subsection{Bending test properties}

Figure 11 shows the force-deflection relationship of PP and its composites with various fillers. In addition, Figure 12 shows their bending modulus of elasticity (MOE). Similar linear initial slope and softening pattern can be seen for the bending curves as compared to those plotted in Figure 7 for tensile loading. PP/FG5 presents the highest average MOE, and is followed by PP/R5 and PP. PP/R5 exhibits an increase in MOE compared to PP due to its filler contribution. This result is in agreement with Tajvidi and Ebrahimi (2003), who reported that the modulus of elasticity increases with the purified $\alpha$-cellulose, wastepaper fibers, and 


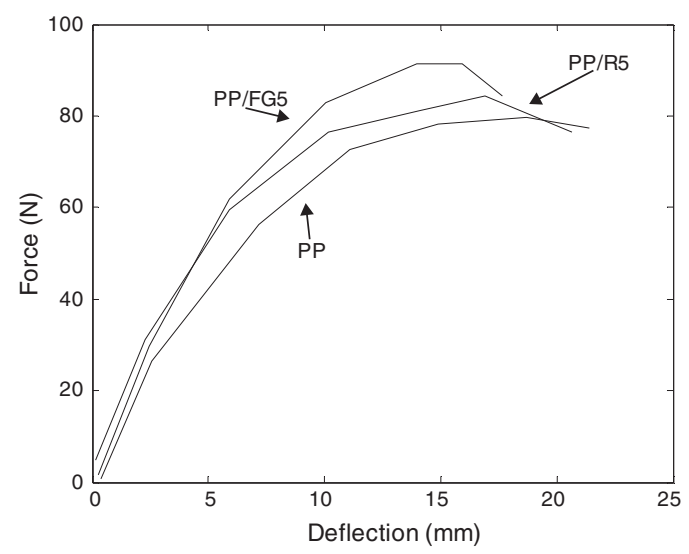

Fig. 11. Bending force-deflection curves for PP and PP with various fillers.

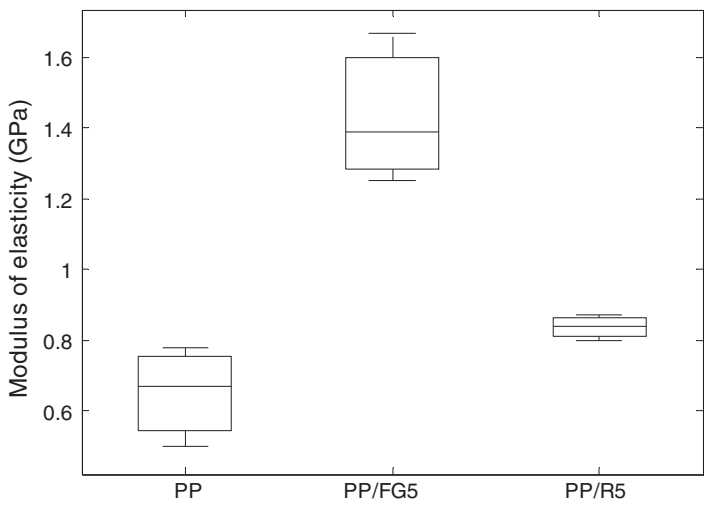

Fig. 12. MOE of neat PP and PP with various fillers.

wood flour filler loadings of 15,25 , and $35 \%$, respectively, when they were used to reinforce polypropylene.

Figure 13 shows the modulus of rupture (MOR) of composites with various fillers and the neat PP. Again, PP/FG5 demonstrates the highest average MOR, and is followed by $\mathrm{PP} / \mathrm{R} 5$ and PP. Incorporating rattan nanoparticle filler into polypropylene is found to increase the MOR better than that of PP alone. Our general observation is aligned with Hassan and Nada (2001), who found that MOR decreases along with the increment of filler content of old newsprint (ONP) fiber as reinforcing component in the polyester composite. In addition, Mirmehdi,

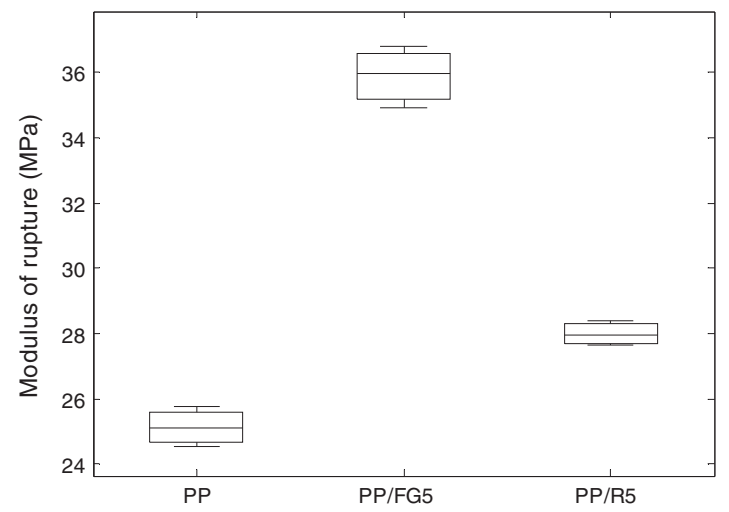

Fig. 13. MOR of neat PP and PP with various fillers.

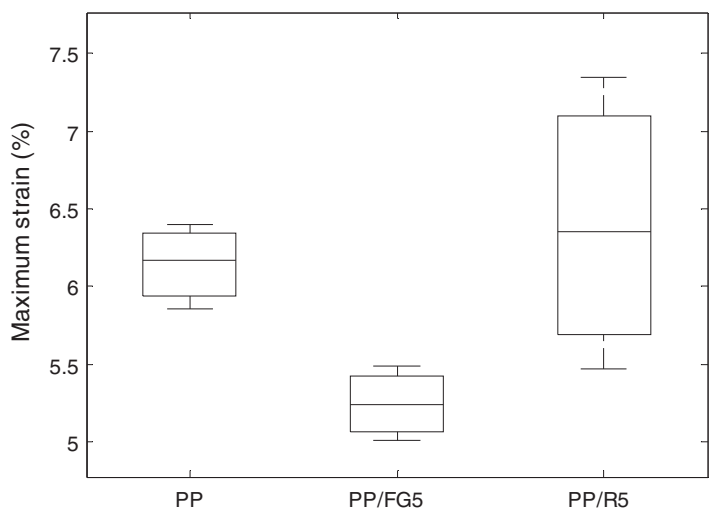

Fig. 14. Maximum strain of neat PP and PP with various fillers.

Zeinaly, and Dabbagh (2014) reported that MOR decreases with the increase in the palm wood flour filler contents of $45 \%$, $60 \%$, and $75 \%$ when incorporated into polyethylene. The present study used fillers of the nanometer size, while Mirmehdi et al. (2014) considered the particle sizes of 25-40 mesh. Therefore, the present study provides an alternative filler size to improve the MOR. Although MOR of PP/R5 is lower than that of PP/R5, it can still be considered as a good alternative due to its nature as a freely available material. Therefore, it offers a better economic advantage over the glass fiber filler.

Figure 14 shows the maximum strains of PP and its composites with various fillers. We can see that PP/R5 has the highest average maximum strain compared to PP and PP/FG5. This result suggests that PP/R5 offers a better ductility versus all considered materials and hence provides the best alternative if such property is of importance in applications. This is generally useful for applications that desire ductility or rather energy absorption as the required behavior of structure, for examples soundproofing and impact resisting materials, to name a few.

\subsection{Hardness properties}

Table 2 lists the Rockwell hardness (HRR) obtained from the hardness test. We find that PP has the lowest average HRR amongst all materials studied. It is noteworthy to see that PP/R5 has the highest average HRR. This relates directly to the good surface morphology of the composites as shown in Figure 5(b). The existence of a good bonding between the rattan filler and matrix of the composite offers better mechanical properties in the current case the hardness. Since natural fillers (rattan, palm, and wood) and polymers (polypropylene and polyethylene) are incompatible for good bonding because of their hydrophilic and hydrophobic behaviors, respectively, several treatments have been implemented to improve the interfacial adhesion between

Table 2

Rockwell hardness (HRR) of PP and its composites.

\begin{tabular}{ll}
\hline Designation & HRR \\
\hline PP & $58.90 \pm 6.37$ \\
PP/FG5 & $68.93 \pm 4.46$ \\
PP/R5 & $79.93 \pm 3.90$ \\
\hline
\end{tabular}


these materials by the incorporation of a coupling agent such as maleic anhydride. This is in addition to the use of smaller size particles as a filler, which offers a greater surface area. Various works have reported the obvious enhancement in the biocomposites properties due to the use of the coupling agent, in terms of mechanical (Dogu \& Kaynak, 2016; Sombatsompop et al., 2005; Thwe \& Liao, 2003) and physical behaviors (Essabir et al., 2016). In general, the surface morphology and certain mechanical properties, for instance, the average hardness and maximum strain were enhanced, indicating an improved interaction (compatible) between the matrix and filler.

Another possible reason for the highest average HRR of $\mathrm{PP} / \mathrm{R} 5$ is that it has the highest crystallinity. Several studies have reported that the crystallinity affects a great deal the composite mechanical properties (Mi et al., 1997; Talbott et al., 1987), for instance, Talbott et al. (1987) observed that the tensile strength and tensile modulus of PEEK 150 polymer were increased with the rise in crystallinity.

\section{Conclusions}

The present study examined the physical, mechanical as well as thermal properties of PP and its composites, i.e., PP/FG5 and PP/R5. We focused on the effects of a small content of rattan with filler sizes of nanoparticle range when incorporated into polypropylene. It was found from the parametric choice of the current study that the rattan particle sizes reduced to the minimum at the milling period of $30 \mathrm{~min}$. It was observed that PP/R5 showed the highest degree of crystallinity compared to PP and PP/FG5. Surface morphology of the PP/R5 was in general well distributed and hence better than the other materials considered. Attributing to this, PP/R5 also exhibited the highest average HRR. Although PP/FG5 demonstrated the greatest performance in terms of MOE and MOR, PP/R5 properties in terms of tensile modulus, tensile strength, and maximum elongation were in the same order with the former. In addition, the highest maximum strain was achieved by PP/R5, a property that is correlated to a good energy absorption behavior. More importantly, the major weakness of natural fiber composite, i.e., the bonding matter can be addressed with the use of a finer sized particle, that is, in the nanometer range. This offers a possibility for the improvement of natural material in various engineering applications in the future.

These results provide an alternative in using the natural rattan to replace glass fiber as filler in polypropylene. It is essential to appreciate from the current study that several advantages are exhibited by the rattan filler in terms of improving the surface morphology and hardness properties of the composites, better than the synthetic fibers. Therefore, the findings of this study have a number of important implications for future practice, for example in manufacturing helmet or vehicle structural components, which are the subjects of our ongoing investigation. Further experimental studies are needed to measure the performance of the natural composite materials in industrial products, especially matters related to their bonding to the matrix.

\section{Conflict of interest}

The authors have no conflicts of interest to declare.

\section{Acknowledgment}

The authors thank the Directorate of Higher Education, Ministry of National Education and Culture, Indonesia for funding the present work under the BOPTN Research Grant (DIPA023.04.2.189772/2014).

\section{References}

Alves, C., Ferrão, P. M. C., Silva, A. J., Reis, L. G., Freitas, M., Rodrigues, L. B., et al. (2010). Ecodesign of automotive components making use of natural jute fiber composites. Journal of Cleaner Production, 18(4), 313-327.

Amash, A., \& Zugenmaier, P. (1998). Study on cellulose and xylan filled polypropylene composites. Polymer Bulletin, 40, 251-258.

Arrakhiz, F. Z., Elachaby, M., Bouhfid, R., Vaudreuil, S., Essassi, M., \& Qaiss, A. (2012). Mechanical and thermal properties of polypropylene reinforced with alfa fiber under different chemical treatment. Materials \& Design, 35 318-322.

Ashori, A. (2008). Wood-plastic composites as promising green-composites for automotive industries. Bioresource Technology, 99(11), 4661-4667.

Ataeefard, M., \& Moradian, S. (2011). Surface properties of polypropylene/organoclay nanocomposites. Applied Surface Science, 257(6), 2320-2326.

Bahari, S. A., \& Krause, A. (2016). Utilizing Malaysian bamboo for use in thermoplastic composites. Journal of Cleaner Production, 110, 16-24.

Balakrishna, N. S., Ismail, H., \& Othman, N. (2012). The effects of rattan filler loadings on properties of rattan powder-filled polypropylene composites. BioResources, 7(4), 5677-5690.

Balakrishna, N. S., Ismail, H., \& Othman, N. (2014). Polypropylene/rattan powder/kaolin hybrid composites: Processing, mechanical and thermal properties. Polymer-Plastics Technology and Engineering, 53(5), 451-458.

Baniasadi, H., Ramazani, S. A. A., \& Javan, N. S. (2010). Investigation of in situ prepared polypropylene/clay nanocomposites properties and comparing to melt blending method. Materials \& Design, 31(1), 76-84.

Chaisan, W., Yimnirun, R., \& Ananta, S. (2009). Effect of vibro-milling time on phase formation and particle size of barium titanate nanopowders. Ceramics International, 35(1), 173-176.

Dogu, B., \& Kaynak, C. (2016). Behavior of polylactide/microcrystalline cellulose biocomposites: Effects of filler content and interfacial compatibilization. Cellulose, 23(1), 611-622.

Essabir, H., Bensalah, M. O., Rodrigue, D., Bouhfid, R., \& Qaiss, A. (2016) Structural, mechanical and thermal properties of bio-based hybrid composites from waste coir residues: Fibers and shell particles. Mechanics of Materials, 93, 134-144.

Essabir, H., Hilali, E., Elgharad, A., El Minor, H., Imad, A., Elamraoui, A., et al. (2013). Mechanical and thermal properties of bio-composites based on polypropylene reinforced with nut-shells of argan particles. Materials \& Design, 49, 442-448.

Goyal, R. K., Tiwari, A. N., Mulik, U. P., \& Negi, Y. S. (2007). Novel high performance $\mathrm{Al}_{2} \mathrm{O}_{3}$ /poly(ether ether ketone) nanocomposites for electronics applications. Composites Science and Technology, 67(9), 1802-1812.

Hassan, M. L., \& Nada, A.-A. M. A. (2001). Recycled old newsprint fibers as a reinforcing filler in molded polyester composites. Journal of Applied Polymer Science, 80, 2018-2023.

Inkyo, M., Tahara, T., Iwaki, T., Iskandar, F., Hogan, C. J., Jr., \& Okuyama, K. (2006). Experimental investigation of nanoparticle dispersion by beads milling with centrifugal bead separation. Journal of Colloid and Interface Science, 304(2), 535-540.

Ismail, H., Edyham, M. R., \& Wirjosentono, B. (2002). Bamboo fibre filled natural rubber composites: The effects of filler loading and bonding agent. Polymer Testing, 21(2), 139-144. 
Jamil, M. S., Ahmad, I., \& Abdullah, I. (2006). Effects of rice husk filler on the mechanical and thermal properties of liquid natural rubber compatibilized high-density polyethylene/natural rubber blends. Journal of Polymer Research, 13(4), 315-321.

Joshi, S. V., Drzal, L. T., Mohanty, A. K., \& Arora, S. (2004). Are natural fiber composites environmentally superior to glass fiber reinforced composites? Composites Part A: Applied Science and Manufacturing, 35(3), 371-376.

Khamman, O., Chaisan, W., Yimnirun, R., \& Ananta, S. (2007). Effect of vibro-milling time on phase formation and particle size of lead zirconate nanopowders. Materials Letters, 61(13), 2822-2826.

Kim, S.-J., Moon, J.-B., Kim, G.-H., \& Ha, C.-S. (2008). Mechanical properties of polypropylene/natural fiber composites: Comparison of wood fiber and cotton fiber. Polymer Testing, 27(7), 801-806.

Lim, S. H., Zeng, K. Y., \& He, C. B. (2010). Morphology, tensile and fracture characteristics of epoxy-alumina nanocomposites. Materials Science and Engineering: A, 527, 5670-5676.

Lin, Y., Chen, Y., Zeng, Z., Zhu, J., Wei, Y., Li, F., et al. (2015). Effect of ZnO nanoparticles doped graphene on static and dynamic mechanical properties of natural rubber composites. Composites Part A: Applied Science and Manufacturing, 70, 35-44.

Lopes, D., Ferreira, M. J., Russo, R., \& Dias, J. M. (2015). Natural and synthetic rubber/waste-ethylene-vinyl acetate composites for sustainable application in the footwear industry. Journal of Cleaner Production, 92, 230-236.

Mi, Y., Chen, X., \& Guo, Q. (1997). Bamboo fiber-reinforced polypropylene composites: Crystallization and interfacial morphology. Journal of Applied Polymer Science, 64(7), 1267-1273.

Mirmehdi, S. M., Zeinaly, F., \& Dabbagh, F. (2014). Date palm wood flour as filler of linear low-density polyethylene. Composites Part B: Engineering, $56,137-141$.

Mittal, V. (2013). Polymer nanocomposite foams. Florida: CRC Press.

Muniandy, K., Ismail, H., \& Othman, N. (2012). Effects of partial replacement of rattan powder by commercial fillers on the properties of natural rubber composites. BioResources, 7(4), 4640-4657.

Nikmatin, S. (2012). Bionanocomposite produced by rattan filler as a substitute glass fiber on vehicle components $\mathrm{PhD}$ Thesis. Bogor Agricultural University.

Nikmatin, S., Syafiuddin, A., Kueh, A. B. H., \& Purwanto, Y. A. (2015). Effects of nanoparticle filler on thermo-physical properties of rattan powder-filled polypropylene composites. Jurnal Teknologi, 77(16), 181-187.
Ochi, S. (2008). Mechanical properties of kenaf fibers and kenaf/PLA composites. Mechanics of Materials, 40, 446-452.

Qiu, W., Zhang, F., Endo, T., \& Hirotsu, T. (2003). Preparation and characteristics of composites of high-crystalline cellulose with polypropylene: Effects of maleated polypropylene and cellulose content. Journal of Applied Polymer Science, 87(2), 337-345.

Ruksakulpiwat, Y., Sridee, J., Suppakarn, N., \& Sutapun, W. (2009). Improvement of impact property of natural fiber-polypropylene composite by using natural rubber and EPDM rubber. Composites Part B: Engineering, 40(7), 619-622.

Sombatsompop, N., Yotinwattanakumtorn, C., \& Thongpin, C. (2005). Influence of type and concentration of maleic anhydride grafted polypropylene and impact modifiers on mechanical properties of PP/wood sawdust composites. Journal of Applied Polymer Science, 97(2), 475-484.

Tajvidi, M., \& Ebrahimi, G. (2003). Water uptake and mechanical characteristics of natural filler-polypropylene composites. Journal of Applied Polymer Science, 88(4), 941-946.

Talbott, M. F., Springer, G. S., \& Berglund, L. A. (1987). The effects of crystallinity on the mechanical properties of PEEK polymer and graphite fiber reinforced PEEK. Journal of Composite Materials, 21(11), 1056-1081.

Thwe, M. M., \& Liao, K. (2003). Durability of bamboo-glass fiber reinforced polymer matrix hybrid composites. Composites Science and Technology, 63, 375-387.

Versino, F., López, O. V., \& García, M. A. (2015). Sustainable use of cassava (Manihot esculenta) roots as raw material for biocomposites development. Industrial Crops and Products, 65, 79-89.

Vilaseca, F., Valadez-Gonzalez, A., Herrera-Franco, P. J., Pèlach, M. À., López, J. P., \& Mutjé, P. (2010). Biocomposites from abaca strands and polypropylene. Part I: Evaluation of the tensile properties. Bioresource Technology, 101(1), 387-395.

Wang, Z., Lu, Y., Ding, J., Zhang, L., \& Chan, T. W. (2016). Preparation of nano-reinforced thermal conductive natural rubber composites. Polymer Composites, 37(3), 771-781.

Zhang, M., \& Singh, R. P. (2004). Mechanical reinforcement of unsaturated polyester by $\mathrm{Al}_{2} \mathrm{O}_{3}$ nanoparticles. Materials Letters, 58, 408-412. 